\title{
Preparatory process preceding the 2014 eruption of Mount Ontake volcano, Japan: insights from precise leveling measurements
}

\author{
Masayuki Murase ${ }^{1 *}$, Fumiaki Kimata ${ }^{2}$, Yoshiko Yamanaka ${ }^{3}$, Shinichiro Horikawa ${ }^{3}$, Kenjiro Matsuhiro ${ }^{3}$, \\ Takeshi Matsushima ${ }^{4}$, Hitoshi Mori ${ }^{5}$, Takahiro Ohkura ${ }^{6}$, Shin Yoshikawa ${ }^{6}$, Rikio Miyajima ${ }^{2}$, Hiroyuki Inoue ${ }^{6}$, \\ Taketoshi Mishima ${ }^{6}$, Tadaomi Sonoda ${ }^{7}$, Kazunari Uchida ${ }^{4}$, Keigo Yamamoto ${ }^{7}$ and Harushisa Nakamichi ${ }^{7}$
}

\begin{abstract}
Preparatory activity preceding the 2014 eruption of Mount Ontake volcano was estimated from vertical deformation detected using a precise leveling survey. Notable uplift (2006-2009) and subsidence (2009-2014) were detected on the eastern flank of the volcano. We estimated pressure source models based on the vertical deformation and used these to infer preparatory process preceding the 2014 eruption. Our results suggest that the subsidence experienced between 2009 and 2014 (including the period of the 2014 eruption) occurred as a result of a sill-like tensile crack with a depth of $2.5 \mathrm{~km}$. This tensile crack might inflate prior to the eruption and deflate during the 2014 activity. A two-tensile-crack model was used to explain uplift from 2006 to 2009. The geometry of the shallow crack was assumed to be the same as the sill-like tensile crack. The deep crack was estimated to be $2 \mathrm{~km}$ in length, $4.5 \mathrm{~km}$ in width, and $3 \mathrm{~km}$ in depth. Distinct uplifts began on the volcano flanks in 2006 and were followed by seismic activities and a small phreatic eruption in 2007. From the partially surveyed leveling data in August 2013, uplift might continue until August 2013 without seismic activity in the summit area. Based on the uplift from 2006 to 2013, magma ascended rapidly beneath the summit area in December 2006, and deep and shallow tensile cracks were expanded between 2006 and 2013. The presence of expanded cracks between 2007 and 2013 has not been inferred by previous studies. A phreatic eruption occurred on 27 September 2014, and, following this activity, the shallow crack may have deflated.
\end{abstract}

Keywords: Mount Ontake volcano, Preparatory process, Precise leveling survey, Vertical deformation, Pressure source

\section{Introduction}

On 27 September 2014, a sudden phreatic eruption occurred at the summit of Mount Ontake volcano, located at the southern end of the Northern Japan Alps, central Japan. The eruption took 63 lives and represented the worst volcanic disaster in post-World War II Japanese history.

Mount Ontake volcano is the second highest stratovolcano in Japan. Throughout its eruption history, it has produced mainly andesite lavas and pyroclastics, including minor amounts of rhyolite, dacite, and basalt. The volcano was considered to be dormant since its last eruptive activity

\footnotetext{
* Correspondence: murase@chs.nihon-u.ac.jp

1 Department of Geosystem Sciences, College of Humanities and Sciences, NIHON University, 3-25-40, Sakurajosui, Setagaya-ku, Tokyo 156-8550, Japan Full list of author information is available at the end of the article
}

approximately 23,000 years ago (Yamada and Kobayashi 1988); however, recent studies indicated that phreatic eruptions have occurred during the past 6000 years (Kimura and Yoshida 1999; Matsumoto and Kobayashi 1995).

Volcano research and monitoring are important for the understanding volcanic activity and for the mitigation of volcanic hazards. Geodetic, geophysical, and geochemical monitoring techniques are commonly used for detecting signs of volcanic unrest. Seismic monitoring has recently revealed micro-seismic activity, including volcano-tectonic (VT) earthquakes, tremors, long-period (LP) earthquakes, and very long-period (VLP) earthquakes, in the summit area of Mount Ontake volcano (Nakamichi et al. 2009). In addition, geochemical monitoring (e.g., $\delta 13 \mathrm{C}$ of $\mathrm{CO}_{2}$ and $3 \mathrm{He} / 4 \mathrm{He}$ ratios) has focused on the hot springs of the

\section{Springer}

(C) 2016 Murase et al. Open Access This article is distributed under the terms of the Creative Commons Attribution 4.0 International License (http://creativecommons.org/licenses/by/4.0/), which permits unrestricted use, distribution, and reproduction in any medium, provided you give appropriate credit to the original author(s) and the source, provide a link to the Creative Commons license, and indicate if changes were made. 
eastern flank of the volcano (Sano et al. 1984). However, deformation in the area around Mount Ontake volcano has not been extensively studied.

Continuous global navigation satellite system (GNSS) benchmarks detected deformation on the volcano flanks prior to a small 2007 eruption, and pressure source models were proposed (Geospatial Information Authority of Japan (GSI) 2008; Ishikawa 2008; Meteorological Research Institute, Japan (MRI) and Japan Meteorological Agency (JMA) 2007). Before the 2014 eruption, deformation initiated from early September 2014 and was detected by a tiltmeter at Tanohara $(4 \mathrm{~km}$ southeast of the summit; JMA 2014). However, the GNSS data did not show clear precursory deformation between 2007 and September 2014. Volcanic-hydrothermal activity is commonly thought to cause phreatic eruptions, but the associated deformation can be difficult to detect using GNSS measurements, as variations are too small and too localized oftentimes (Daita et al. 2009; Murase et al. 2014). While tiltmeters are sensitive enough to detect early signs of volcanic unrest, they are not adequate for monitoring long-term deformation.

Some studies have reported ground deformation detected using precise leveling surveys on active volcanoes, with the results allowing for the prediction of eruptive activity. On Sakurajima Island, Japan, uplift was detected on Sakurajima volcano, while around the Aira Caldera, deformation in the center of the caldera can be explained by the inflation of a spherical source (Yamamoto et al. 2013). Yamamoto et al. (2013) used this data to suggest the imminent potential of new and intensive eruptive activity at Sakurajima volcano. In the Campi Flegrei caldera, Italy, the geometry and density of a deformation source has been estimated from leveling, electronic distance measurement (EDM), and gravity surveys. The estimated density of the source was considered to be almost the same as that of water, unambiguously suggesting the presence of geothermal fluid (Battaglia et al. 2006). At the Tatun Volcano Group, Taiwan, a shallow spherical source was proposed as a plausible model to explain small uplift in a fumarolic area, and the imminent potential of phreatic activity was also suggested (Murase et al. 2014).

In this study, notable uplift (2006-2009) and subsidence (2009-2014) on the eastern flank of Mount Ontake volcano were detected using precise leveling surveys. Based on this deformation pattern, we suggest that magma intruded the shallow plumbing system between 2006 and 2014.

\section{Previous geodetic and seismic studies of Mount Ontake volcano (2006-2014)}

In data from the continuous GNSS survey, a rapid change was first detected on the baseline between both flanks of Mount Ontake volcano between December 2006 and January 2007, while a minor change was detected from
January 2007 to February 2007 (GSI 2008). A small phreatic eruption was identified by ash-fall deposits in the fumarolic region of the southern part of the summit in late March 2007 (JMA 2008b). However, from March 2007 to September 2014, no clear deformation associated with volcanic-hydrothermal activity was detected by the continuous GNSS survey. However, MRI and JMA (2007) reported GNSS data that showed a minor inflation $(\sim 5 \mathrm{~mm})$ in a very small region of the summit area from February 2007 to April 2007. At the beginning of September 2014, a slight increase was detected on some baselines between both flanks of Mount Ontake volcano. This continued into mid-September, after which slight contraction was observed between mid-September 2014 and December 2014 (GSI 2015).

To explain the deformation signal observed from far-field observations between 2006 and 2007, GSI (2008) proposed a model consisting of a dike at a 5.4- $\mathrm{km}$ depth and a spherical source at a $10-\mathrm{km}$ depth. In contrast, MRI and JMA (2007) and Ishikawa (2008) used data including near-field observations for their modeling. MRI and JMA (2007) proposed a spherical source at a $0-\mathrm{km}$ depth and a dike at a $2.5-\mathrm{km}$ depth. Ishikawa (2008) proposed a two-dike model with depths of 0 and $4 \mathrm{~km}$.

At the end of December 2006, seismic activity increased beneath the summit area (JMA 2008a). VT earthquakes occurred beneath the summit at depths between $1 \mathrm{~km}$ above sea level and $3 \mathrm{~km}$ below sea level (Nakamichi et al. 2009). A VLP earthquake occurred on 25 January 2007, when VT activity had almost ceased; thus, VT activity was followed by the occurrence of LP earthquakes and tremors.

Seismic activity peaked in March 2007 when the small phreatic eruption occurred but subsided to almost no activity by mid-2007. Seismicity continued at a low level until September 2014. From 10 to 11 September 2014, VT earthquakes increased rapidly. Subsequently, LP earthquakes occurred five times from 14 to 24 September. Finally, the phreatic eruption occurred on 27 September 2014. Pre-eruptive seismic activity was low and of short duration, as compared with that preceding the 2007 eruption.

On the other hand, earthquake swarms have been observed continuously on the south-southeastern flank of Mount Ontake volcano since 1978. The epicenter of the swarm migrated from the southern flank to the eastern flank in 1993 (Nagoya University 1999), and swarm activity still continues today. Our repeated precise leveling survey, conducted since 1999, revealed uplift of 3-6 $\mathrm{mm}$ /year in and around the swarm region from 2002 to 2006 (Kimata et al. 2003, 2004, 2011). In this study, we mainly focused on data of the precise leveling surveys from 2006 to 2014 in order to highlight the pre-eruptive activity at Mount Ontake volcano prior to the 2014 eruption. 


\section{Methodology}

\section{Data collection}

We established leveling routes on the eastern flank of Mount Ontake volcano in 1999 (Fig. 1) in order to detect deformation resulting from seismic swarm activity (Kimata and Miyajima 2001). The first route was extended to Yashikino village in 2002. In order to improve the spatial layout of the benchmarks, a branched leveling route was established in 2004 (the Kiso-Onsen route). Together, these routes are $23 \mathrm{~km}$ in length and include a total of 60 benchmarks. The cumulative height difference along the leveling routes is $\sim 350 \mathrm{~m}$ (Fig. 2b). Benchmarks consist of small brass nails installed on concrete bases at intervals of $\sim 300 \mathrm{~m}$. Precise leveling was conducted using DNA03 (Leica Geosystems) and NA3003 (Leica Geosystems) and SDL1 (Sokkia Topcon) digital levels with bar-coded spear invar leveling rods. Precise leveling surveys were conducted along these routes in April 2006, April 2007, May 2008, April 2009, August 2013, and October 2014 (Fig. 2a). In April 2006, April 2007, and October 2014, all of the routes were measured, while the routes from benchmark BM25 to the west were measured in April 2008 and April 2009. In August 2013, a short distance between benchmarks BM205 and BM310 was measured. Short bridges and tunnels were not surveyed along the leveling route because of road construction and traffic. Deformation resulting from these points was assumed to be negligible, because construction covered only short distances (less than $100 \mathrm{~m}$ ). Survey results prior to 2006 were discussed in Kimata et al. (2004, 2011). Deformation was calculated using benchmarks BM34 (April 2006 and April 2007), BM25 (April 2008, April 2009, and October 2014), and BM205 (August 2013) as reference points.

\section{Leveling survey errors}

In general, the error of precise leveling increases with the square of the distance of the observed route. The Geospatial Information Authority of Japan defines the threshold for closure of a round-trip survey as

$$
e=2.5 \sqrt{S}
$$

where $e$ is the threshold for closure of a round-trip survey $(\mathrm{mm})$ and $S$ is the distance $(\mathrm{km})$ between two benchmarks. On this basis, measurements were repeated until the value of closure became smaller than the threshold given by Eq. (1). In most cases, the value of closure was sufficiently smaller than the threshold.

Leveling routes are usually laid out in the form of a loop, in order to check for survey errors. However, we could not adopt a looped leveling route because of road conditions in the mountainous study area. To define the survey error $(\sigma)$ of a non-loop leveling route, Pelton and Smith (1982) presented the following equation:

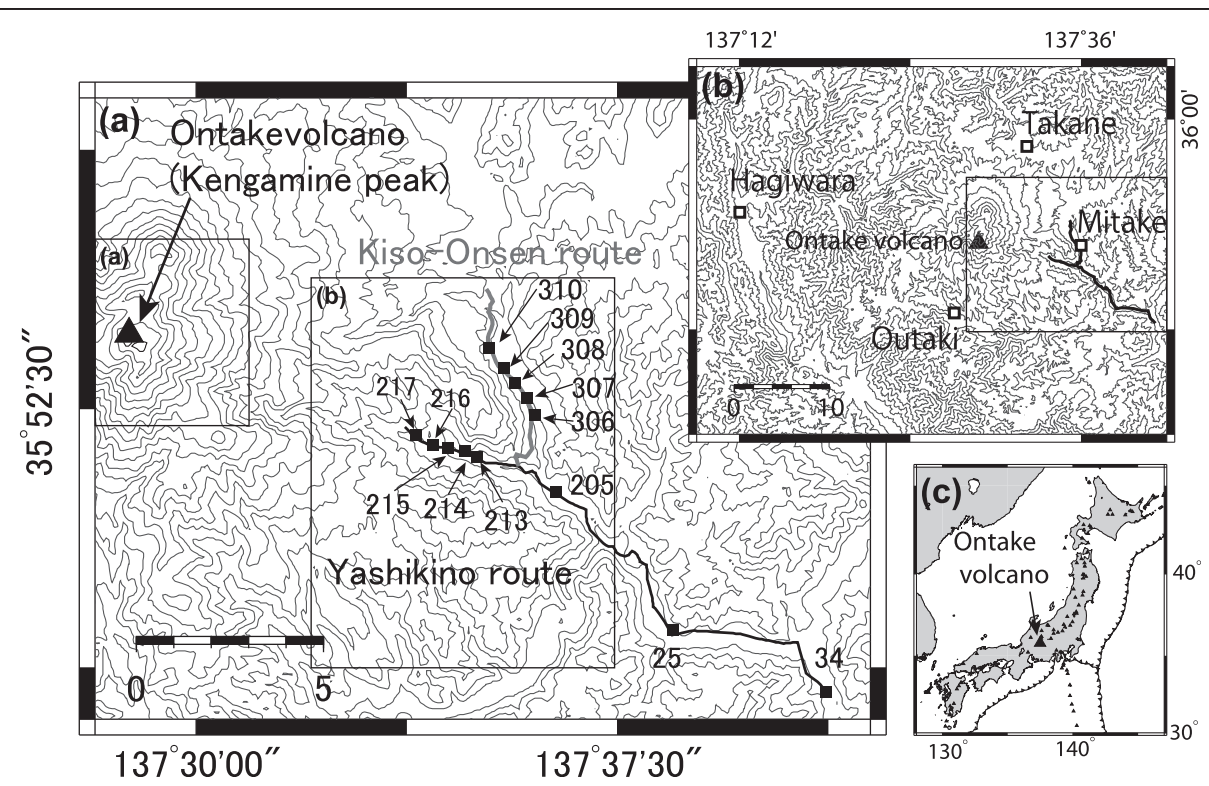

Fig. 1 Location maps of Mount Ontake volcano. a Location map of Mount Ontake volcano showing the Yashikino leveling route (black line) and the Kiso-Onsen leveling route (gray line). The triangle and squares denote the locations of the Kengamine peak of Mount Ontake volcano and the main benchmarks, respectively. The rectangles ( $a$ and $b$ ) denote the research area used to investigate seismic activity (Fig. 10). b Location map showing the GEONET stations (open squares) around Mount Ontake volcano. The rectangle and black line show the area of the location map (a) and the leveling route, respectively. c The map shows the location of active volcanoes (black triangles) in the Japanese islands, with the large triangle denoting Mount Ontake volcano 
(a) Deformations for each survey period (2006-2014)

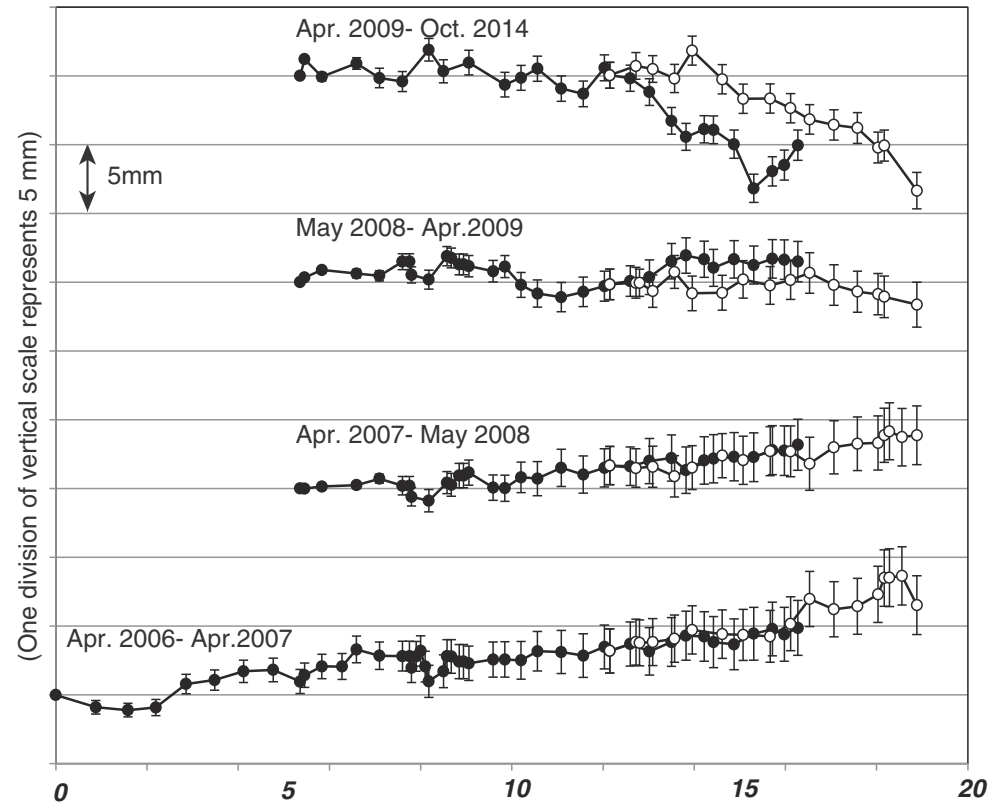

(b) Relative elevation referred to BM34

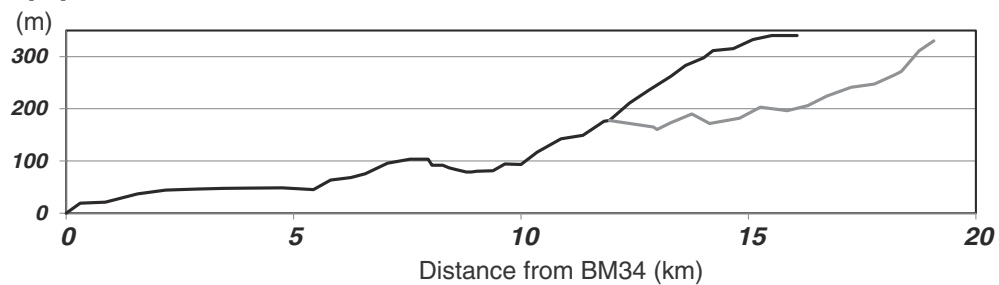

Fig. 2 Vertical deformation and route profiles. a Vertical deformation $(\mathrm{mm})$ for each survey period, as detected by precise leveling of the Yashikino route (black circles) and the Kiso-Onsen route (white circles), from April 2006 to October 2014. Deformation was calculated using benchmarks BM34 (for data between April 2006 and April 2007) and BM25 (for all other data periods) as references (See Fig. 1 for locations of BM34 and BM25). Each division of the vertical scale represents $5 \mathrm{~mm}$ of deformation. Error bars denote the accumulated closing errors from the reference point. b Route profiles using precise leveling surveys. Relative elevations $(\mathrm{m})$ of the benchmarks are with reference to benchmark BM34

$$
\sigma=\frac{\beta}{\sqrt{j}} \sqrt{S},
$$

where $\sigma$ is the random error of a non-loop leveling route $(\mathrm{mm}), \beta$ is a constant related to accuracy, $j$ is a constant related to the number of measurements (here, $j$ is 2), and $S$ is the distance $(\mathrm{km})$ from the reference benchmark. From leveling data at the Long Valley Caldera, Vanicek et al. (1980) calculated the value of $\beta$ to be 0.7 .

We therefore checked the survey error by using the closure difference of the round-trip survey on the Yashikino and Kiso-Onsen routes. The total of all the closure differences was found to be less than $2 \mathrm{~mm}$ (Fig. 3). Most of the closure differences were smaller than the curve $(82 \%)$ calculated from Eq. (2) using $\beta=0.7$ (Fig. 3).

We also considered the scale error, which is considered to be the main factor involved in systematic errors from leveling surveys. A significant cause of such errors is the shift in scale due to thermal expansion of the leveling rod. However, in our survey, we used spear invar rods to minimize thermal expansion. In addition, we made a correction for thermal expansion using the linear expansion coefficient of spear invar. We also took temperature measurements at the time of the leveling surveys in order to estimate the correction value. We additionally checked the influence using a case where the linear expansion coefficient had an uncertainty of $5.0 \times 10^{-7} /{ }^{\circ} \mathrm{C}$, where the temperature difference was $10{ }^{\circ} \mathrm{C}$ and where the maximum relative height from benchmark BM34 was approximately $350 \mathrm{~m}$. A scale error of only $1.75 \mathrm{~mm}$ was estimated, and this value was considered sufficiently small as to not significantly affect the results. Therefore, we concluded that the results were accurate enough to detect a deformation of greater than a few millimeters. 


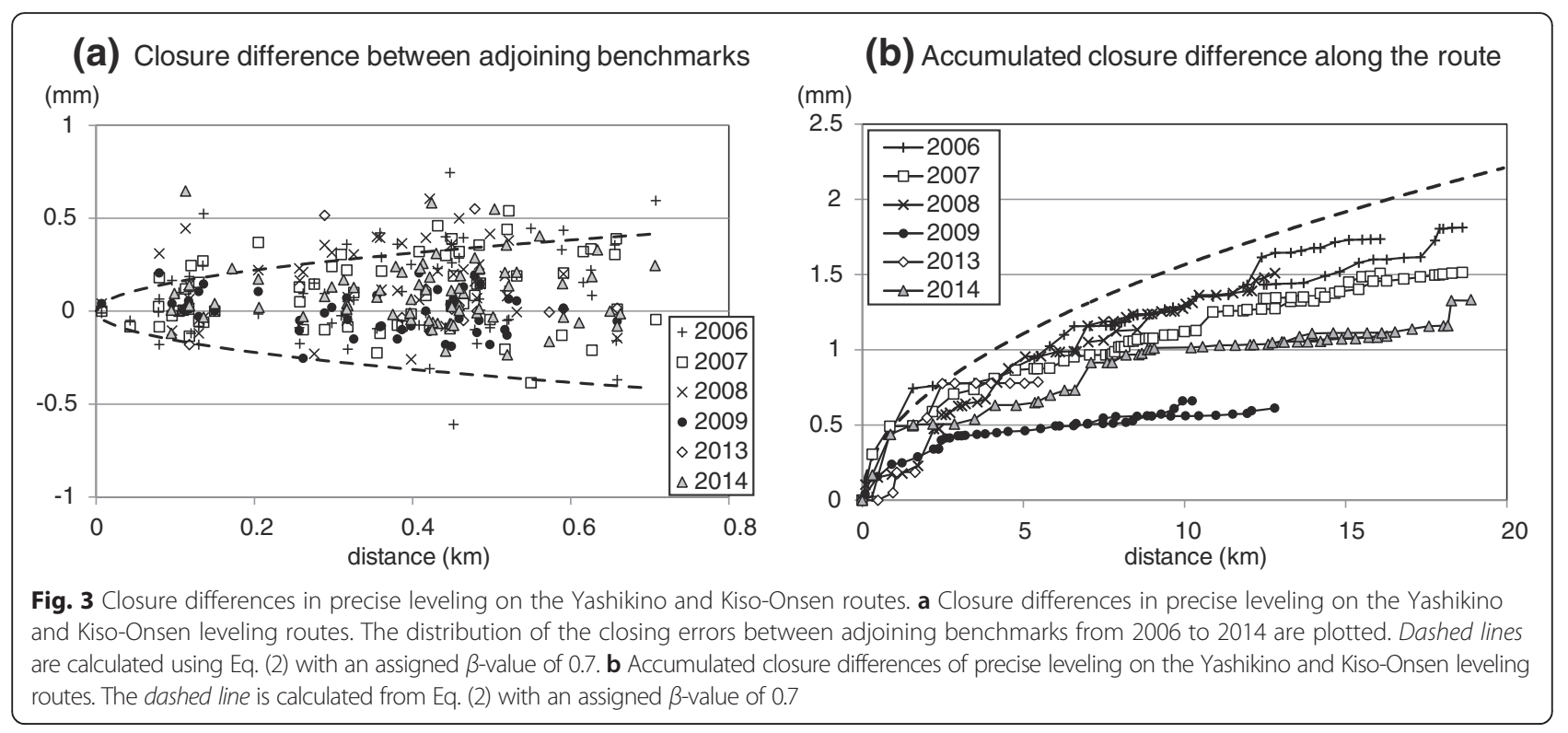

\section{Model selection}

While a number of models have been proposed to explain the deformation observed in GNSS data from 2006 to 2007, a unified model has not been developed. Based on previous studies and leveling results, we hypothesized that the magma intruded the shallow system from 2006 to 2009 but that the 2014 eruption and aftermath were characterized by deflation. In this study, we considered four models (spherical source, tensile crack, spherical source with tensile crack, and two tensile cracks) as candidates for the source model.

We began by modeling the period between 2009 and 2014 because the geometry of the 2014 eruptive fissure provided a useful reference for modeling the shallow source during this period. Our leveling data were insufficient to estimate all parameters of the above models because they were acquired only on the eastern flank of the volcano. In particular, it was difficult to determine an exact geometry of the shallow source. Therefore, the location of the spherical source model was assumed to be beneath the center of the 2014 eruptive fissure, while the location, length, and strike angle for the tensile crack model were assumed from the geometry of the eruptive fissure.

For modeling the period between 2006 and 2014, the geometry of a shallow crack and spherical source was assumed to be the same as that of the 2009-2014 models. For the other models (spherical source with tensile crack, and two tensile cracks), the shallow spherical source or shallow tensile crack assumed the same geometry as in the 2009-2014 models, and all parameters of the deep tensile crack were estimated.

Model parameters were optimized using a genetic algorithm (GA) in order to conform to the deformation observed from 2009 to 2014 and 2006 to 2009. The GA method employs a random walk, and, unlike the conventional Monte Carlo method, it uses a probability rule for searching (Goldberg 1989). The GA method is an effective approach to the volcano deformation modeling (e.g., Irwan et al. 2006). Optimal parameters are selected on the basis of minimizing the fitness function, which is defined as the weighted residual sum of squares. The deformation at each benchmark was calculated using an elevation-modified Mogi model (Fukui et al. 2003; Mogi 1958) and dislocation model (Okada 1992). Details of the GA method were described by Winter et al. (1996).

The four examined models have the trade-off between the goodness-of-fit of the model and the complexity of the model. The goodness for the four examined models was determined based on Akaike's information criteria (AIC; Akaike 1973) calculated as

$$
\begin{aligned}
& \mathrm{AIC}=N\left(\ln 2 \pi \hat{\sigma}^{2}+1\right)+2 K, \\
& \hat{\sigma}^{2}=\frac{\sum_{n=1}^{N}\left(V_{n}^{\text {obs }}-V_{n}^{\text {cal }}\right)^{2}}{N}
\end{aligned}
$$

where $N$ is the total number of benchmarks, $K$ is the total number of model parameters, and $V_{n}^{\text {obs }}$ and $V_{n}^{\text {cal }}$ are the observed and calculated vertical deformations at the $n$th benchmark, respectively. The AIC index, where the model with the lowest AIC value is defined as the best solution, can be used for comparisons between models with different numbers of parameters.

\section{Horizontal deformation}

In this study, the model was estimated based on vertical deformation; however, horizontal deformation should be also considered. We verified our model, estimated from 
the vertical deformation detected by leveling data, using horizontal deformation detected by GNSS. GSI established a dense nationwide GNSS network (GEONET), which began its formal operation in 1996. F3 solutions, provided as daily coordinates by GSI, were used in four GEONET benchmarks (Hagiwara, Takane, Mitake, and Outaki) around Mount Ontake volcano (Fig. 1). The Hagiwara benchmark was used as a reference point for the deformation. We selected data for 10 days in April 2006, April 2009, and October 2014 and calculated the deformation from the differences between the 10-day averages. In the period from April 2009 to October 2014, we removed the coseismic offsets resulting from the 2011 M9 Tohoku earthquake and then estimated and removed postseismic deformation using an exponential function. Time series of the Mitake GEONET benchmark after removal of the coseismic and postseismic effects is shown in Fig. 4. In the vertical component of GNSS (not used here), clear coseismic and postseismic deformation could not be confirmed. Horizontal deformation was calculated according to the models estimated using the precise leveling data and was compared with the observed deformation detected by GNSS in the periods of April 2006 to April 2009 and April 2009 to October 2014.

\section{Results and discussion \\ Vertical deformation}

From April 2006 to April 2007 (during which time the 2007 phreatic eruption occurred), relative vertical deformation between BM34 and BM25 was considered to be negligible ( $0.8 \mathrm{~mm}$; Fig. 2$)$; however, on the Yashikino and Kiso-Onsen routes, $\sim 8 \mathrm{~mm}$ of uplift was detected, followed by a smaller amount of uplift between April 2007 and May 2008 (Fig. 2). From May 2008 to April 2009, a minor uplift was detected only on the Yashikino route. To emphasize the uplift before the 2014 eruption, we stacked the 2006-2009 results (Fig. 5b).

From April 2009 to October 2014, a time period that included the 2014 eruption, $\sim 8 \mathrm{~mm}$ of subsidence was detected on the Yashikino and Kiso-Onsen routes (Figs. 2 and 5), with deformation concentrated in the area to the west of BM205. It is notable that the uplift from 2006 to 2009 was larger than the subsidence from 2009 to 2014. Furthermore, the spatial distribution of deformation from 2009 to 2014 and 2006 to 2009 differed from that of previous periods of deformation (Fig. 5c; Kimata et al. 2011).

\section{Pressure source models and pre-eruptive processes before the 2014 eruption}

For 2009-2014, optimal parameters for the four models (spherical source, tensile crack, spherical source with tensile crack, and two tensile cracks) were estimated on the basis of AIC values (Table 1). Among all the candidates, the sill-like tensile crack model provided the best fit (Table 2). Although the sill-like tensile crack model was chosen as the best model based on AIC, the difference in AIC number for the tensile crack model and the spherical source model is very small. We consider that our study represents the initial stage of precise leveling survey in the Ontake volcano and that establishing new dense leveling routes to definitely distinguish between the tensile crack model and spherical source model will be needed.

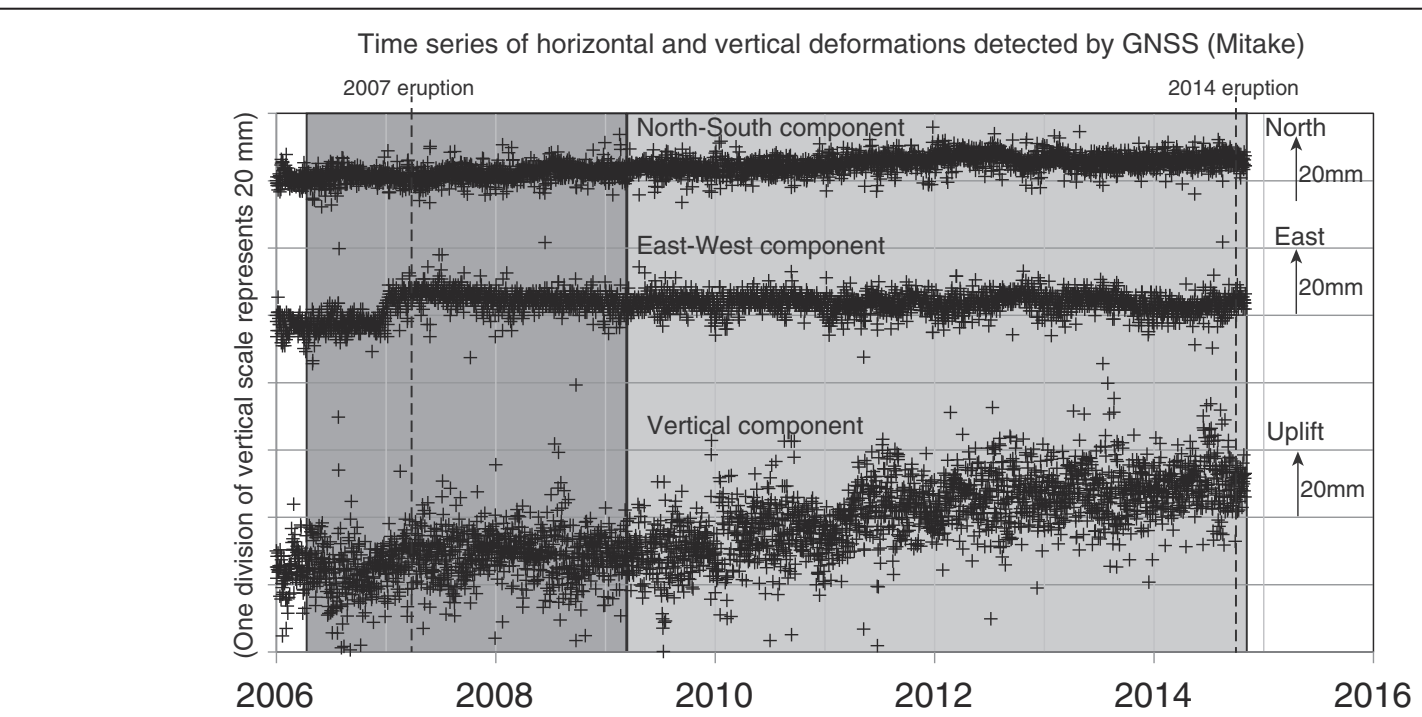

Fig. 4 Time series after removal of the coseismic and postseismic effects of the 2011 M9 Tohoku earthquake in the Mitake GEONET benchmark relative to the Hagiwara GEONET benchmark. Dark- and light-shaded areas represent the periods of April 2006 to April 2009 and April 2009 to October 2014, respectively. The vertical dashed lines denote the occurrence months of the eruptions in 2007 and 2014 


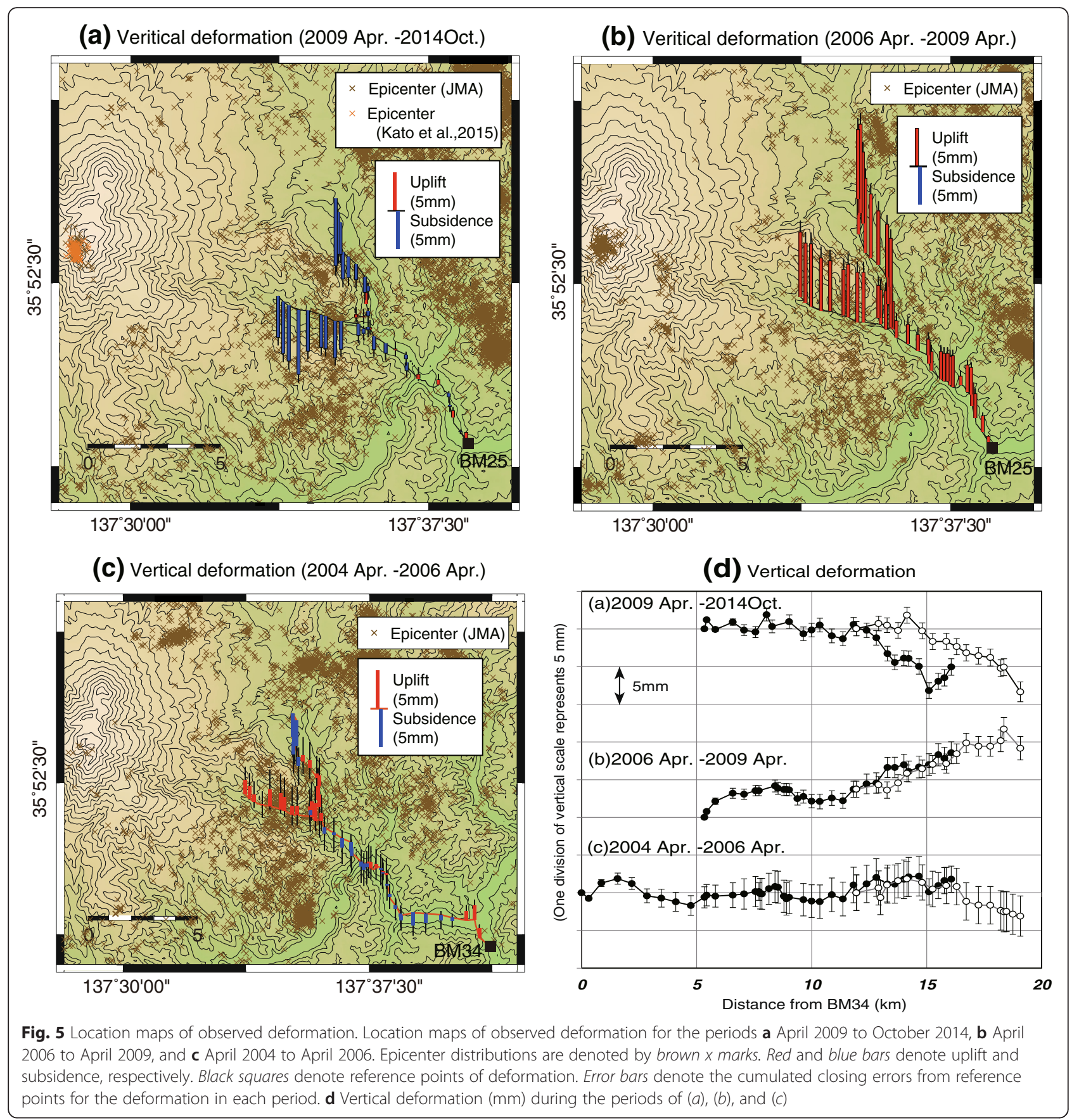

Observed and calculated vertical deformations are shown in Fig. 6, and horizontal deformation based on the sill-like tensile crack model was compared with the deformation detected by GNSS (Fig. 7). Observed horizontal deformation was very small (within a few millimeters). From the time series of the Mitake GEONET benchmark, although the deformation trend seems to be changed from inflation to deflation after the 2014 eruption, the amount of change is as small as that of the observation error (Fig. 4). We believe that the locations of GEONET benchmarks were
Table 1 Akaike's information criteria (AIC) values for each model (2009-2014)

\begin{tabular}{lc}
\hline & AlC \\
\hline Tensile crack model & 159.2 \\
Spherical source model & 160.7 \\
Two-tensile-crack model & 175.2 \\
Model of spherical source with tensile crack & 176.7 \\
\hline
\end{tabular}


Table 2 Tensile crack model (2009-2014)

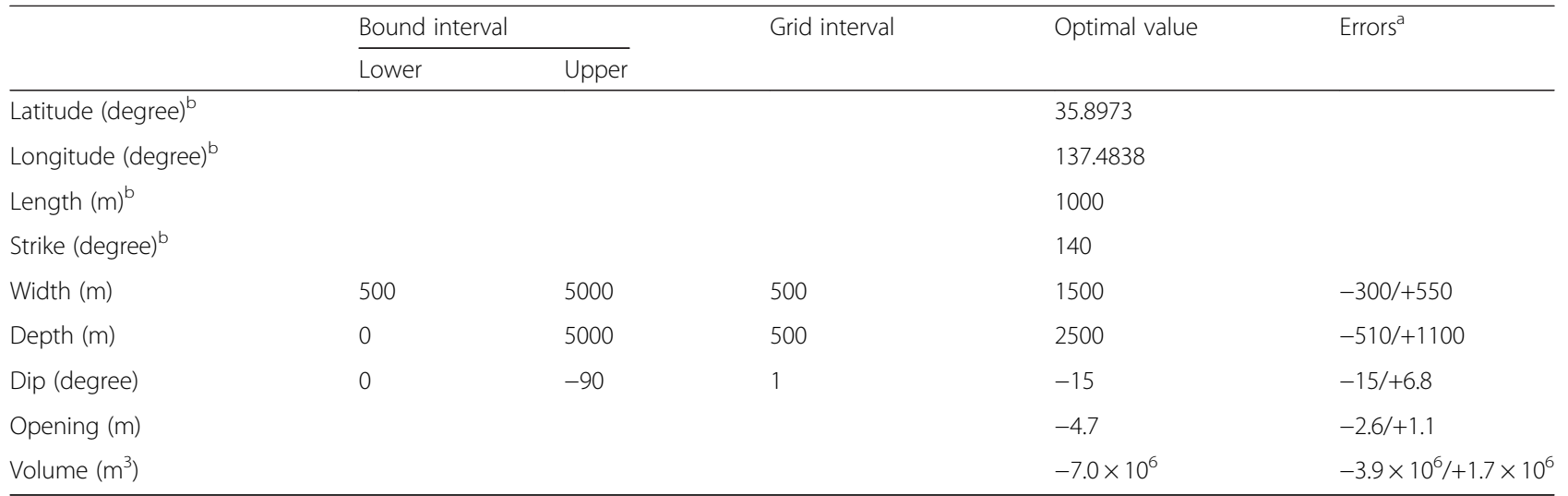

${ }^{a} 95 \%$ confidence level estimated from F-tests (Arnadottir and Segall 1994)

${ }^{b}$ Parameters assumed by the approximately linear distribution of volcanic events in 2014

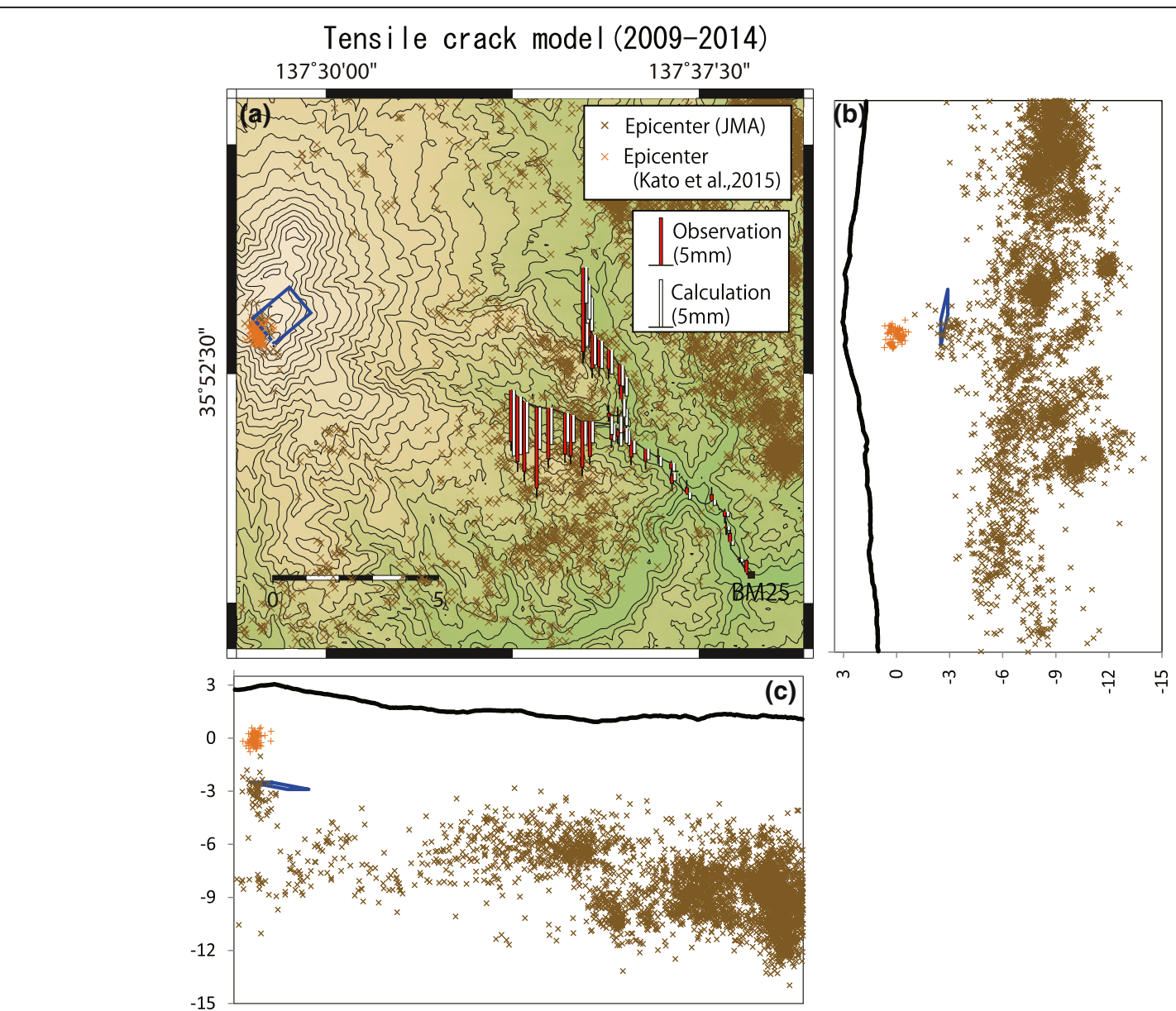

Fig. 6 Vertical deformation and earthquake locations from the tensile crack model. a Observed (red bars) and calculated (white bars) vertical deformations from April 2009 to October 2014 based on the tensile crack model, including the epicenters of earthquakes in and around Mount Ontake volcano. The blue rectangle denotes the location of the shrunken tensile crack. Error bars on the sources show the $95 \%$ confidence level estimated using an F-test (Arnadottir and Segall 1994). b Depth profile of the estimated sources with earthquakes in a latitudinal direction. c Depth profile of the estimated sources with earthquakes in a longitudinal direction 


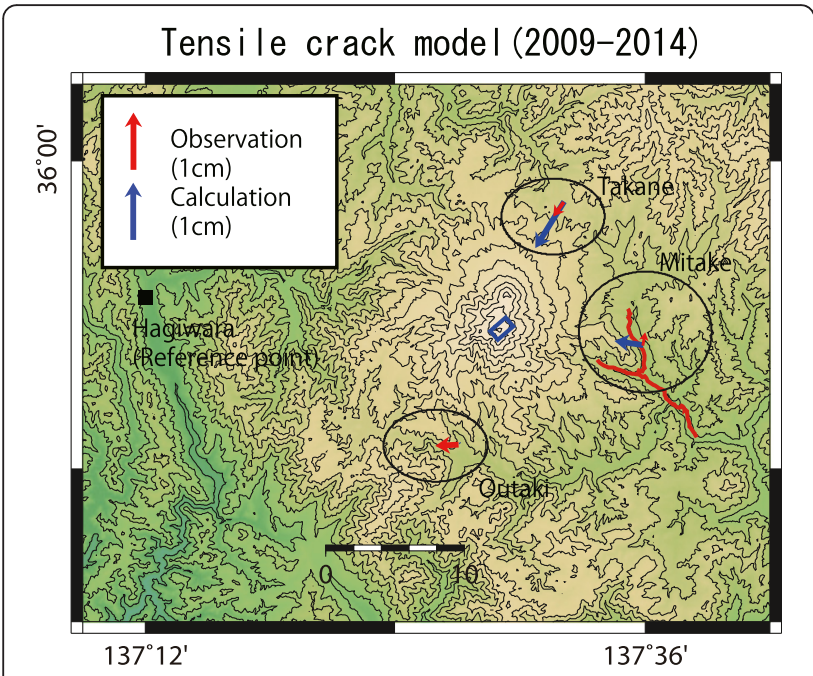

Fig. 7 Horizontal deformation from the tensile crack model. Observed (red arrows) and calculated (blue arrows) horizontal deformations from April 2009 to October 2014 based on the tensile crack model. Error ellipses were described by $3 \sigma$. The blue rectangle denotes the location of the shrunken tensile crack. The red lines and black square denote the locations of the leveling routes and the reference point of the global navigation satellite system (GNSS), respectively

too far to detect the deformation of the 2014 eruption. The calculated horizontal deformations were also very small, and differences between the observed and calculated horizontal deformations were within the $3 \sigma$ error ellipses (Fig. 7). In addition, the vertical deformation of the Mitake GNSS benchmark was shown uplift for 2009-2014 (Fig. 4). The vertical deformation of the Mitake GNSS benchmark is entirely different from that of our leveling survey. In order to detect clear horizontal deformations, the continuous GNSS observation in the summit area will be needed.

The depth of the top of the deflated crack is just beneath precursory activity of VT events (Kato et al. 2015). Yamamoto (2014) reported that thick white fumes and pyroclastic density currents were produced from the 2014 eruptive fissure. GSI (2015) reported that a slight contraction was detected on the GNSS's baselines between both the flanks of Mount Ontake volcano from mid-September 2014 to December 2014. Although the timing of deflation cannot be identified from the leveling data, the deflation of a crack could be caused by the emission of volcanic gases and fluids involving the eruption. VT and LP events might occur by the rising volcanic gases and fluids just above the deflated crack before the eruption. We believe that an increase in magma density was caused by the emission of volcanic volatiles from magma, which was followed by magma drain-back.

For 2006 to 2009, the two-tensile-crack model provided the best fit based on the AIC values (Tables 3 and 4). Observed and calculated vertical deformations are shown in
Table 3 Akaike's information criteria (AIC) values for each model (2006-2009)

\begin{tabular}{lc}
\hline & AlC \\
\hline Tensile crack model & 174.9 \\
Spherical source model & 178.2 \\
Two-tensile-crack model & 155.5 \\
Model of spherical source with tensile crack & 159.7 \\
\hline
\end{tabular}

Fig. 8, and horizontal deformation calculated using the two-tensile-crack model was compared with the deformation detected by GNSS (Fig. 9). Observed horizontal deformation showed a slight inflation. From the time series of the Mitake GEONET benchmark, the East-West component was shown a rapid inflation about half year before the 2007 eruption (Fig. 4). The temporal change of the horizontal deformation on the Mitake GEONET benchmark seems to be consistent with that of the vertical deformation detected by the leveling survey in the period of 2006 to 2009. Although the observed and calculated vertical deformations indicated a similar tendency, the horizontal deformation is not fully explained on the basis of the two-tensile-crack model (Fig. 9). Our leveling data, as we have mentioned before, were insufficient to estimate all parameters of the model because they were acquired only on the eastern flank of the volcano. Therefore, several parameters of the model were assumed from the geometry of the eruptive fissure on the surface. We believe that the mismatch between the observation and the calculation is caused by these doubtful assumptions and that establishing new dense leveling routes and GNSS surveys will be needed for the estimation of all model parameters.

The occurrence of a shallow crack was supported by its inferred depth, which overlapped with that of the VT events associated with the 2007 eruption (JMA 2008a). Therefore, the shallow crack may have existed from at least 2006. As a possible objection of the crack model, volume change of the crack may be difficult to continue for a long period from 2006 to 2014 because a crack shape is easy to cool and become solidified. In order to avoid the solidification of the crack, it may be necessary to supply hot magma continuously from the deeper part and/or to have a thick body of the crack. Within the shallow crack, there is a mismatch between the increasing volume change $(0.9 \times$ $10^{6} \mathrm{~m}^{3}$ from 2006 to 2009) and the decreasing volume change $\left(-7.0 \times 10^{6} \mathrm{~m}^{3}\right.$ from 2009 to 2014$)$. It may be difficult to estimate the accurate volume changes of the twocrack model because of insufficient data in the mountain area. We believe that the increasing volume change is underestimated in our model. On the basis of our results, we believe that a pre-eruptive magma intrusion mainly fed into the shallow crack from 2006 to 2009, representing the main preparatory process of the 2014 eruption. 
Table 4 Two-tensile-crack model (2006-2009)

\begin{tabular}{|c|c|c|c|c|c|c|}
\hline & & \multicolumn{2}{|c|}{ Bound interval } & \multirow{2}{*}{$\begin{array}{l}\text { Grid } \\
\text { interval }\end{array}$} & \multirow{2}{*}{$\begin{array}{l}\text { Optimal } \\
\text { value }\end{array}$} & \multirow[t]{2}{*}{ Errors } \\
\hline & & Lower & Upper & & & \\
\hline \multirow[t]{2}{*}{ Shallow tensile crack } & Opening (m) & & & & 0.6 & $-1.9 /+2.1$ \\
\hline & Volume $\left(\mathrm{m}^{3}\right)$ & & & & $0.9 \times 10^{6}$ & $-2.9 \times 10^{6} /+3.2 \times 10^{6}$ \\
\hline \multirow[t]{9}{*}{ Deep tensile crack } & Latitude (degree) & 35.8689 & 35.9049 & 0.0045 & 35.8869 & $-0.0126 /+0.0293$ \\
\hline & Longitude (degree) & 137.4735 & 137.4847 & 0.0056 & 137.4791 & $-0.0121 /+0.0362$ \\
\hline & Length (m) & 1000 & 5000 & 500 & 2000 & $-400 /+600$ \\
\hline & Strike (degree) & 120 & 180 & 1 & 155 & $-9 /+28$ \\
\hline & Width (m) & 500 & 8000 & 500 & 4500 & $-800 /+1500$ \\
\hline & Depth (m) & 2000 & 10,000 & 500 & 3000 & $-1300 /+5000$ \\
\hline & Dip (degree) & 0 & -90 & 1 & -70 & $-10 /+29$ \\
\hline & Opening (m) & & & & 0.7 & $-0.2 /+1.0$ \\
\hline & Volume $\left(\mathrm{m}^{3}\right)$ & & & & $6.3 \times 10^{6}$ & $-1.7 \times 10^{6} /+9.4 \times 10^{6}$ \\
\hline
\end{tabular}

\section{Model of two tensile cracks (2006-2009)} $137^{\circ} 30^{\prime} 00^{\prime \prime}$
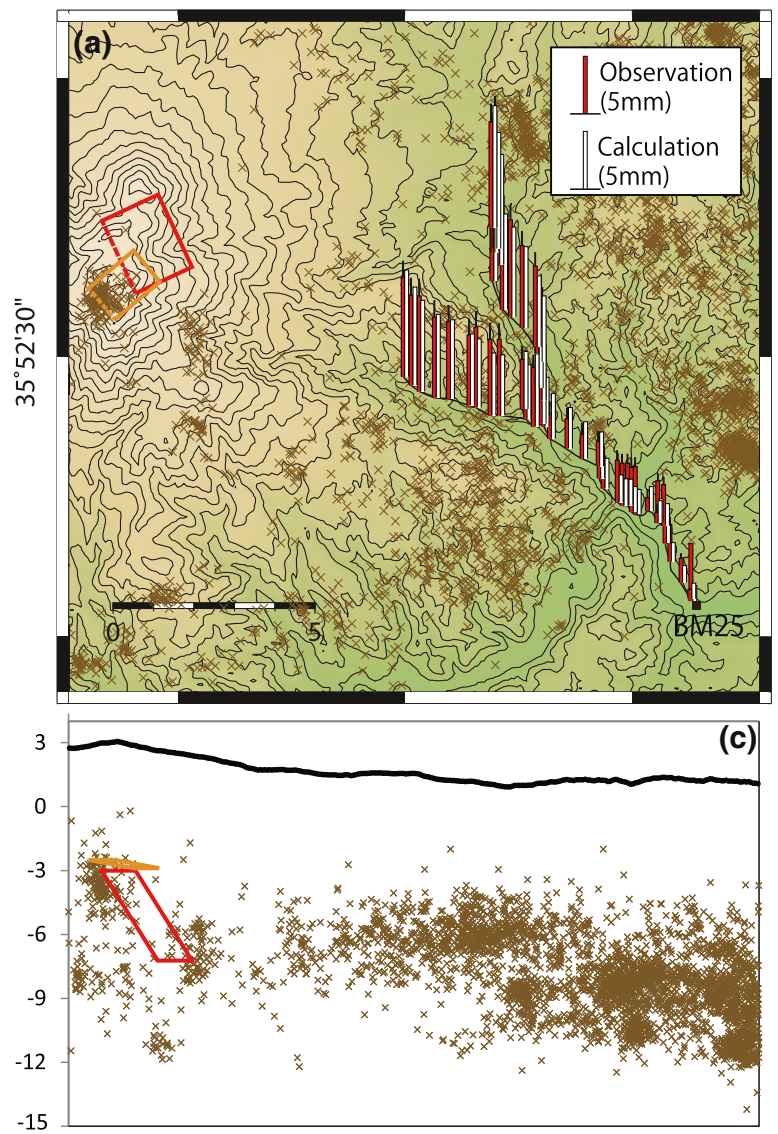

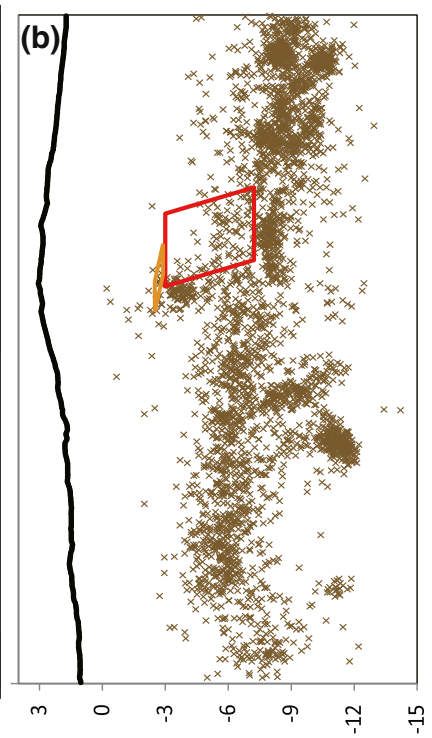

c)

Fig. 8 Vertical deformation and earthquake locations from the two-tensile-crack model. a Observed (red bars) and calculated (white bars) vertical deformations from April 2006 to April 2009 based on the two-tensile-crack model, including the epicenters of earthquakes. Red-and orange-colored rectangles denote the locations of the deep and shallow tensile cracks, respectively. $\mathbf{b}$ Depth profile of the estimated sources with earthquakes in a latitudinal direction. c Depth profile of the estimated sources with earthquakes in a longitudinal direction 


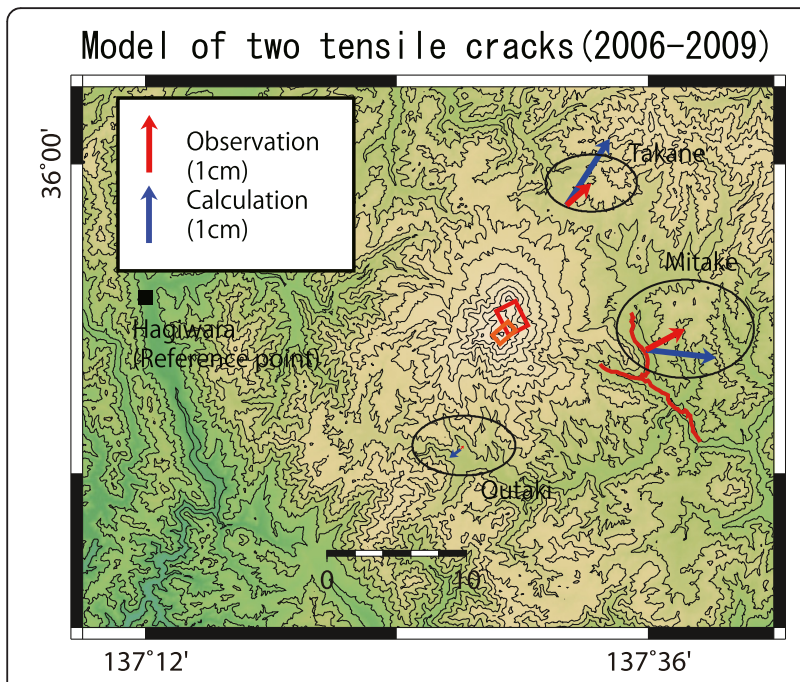

Fig. 9 Horizontal deformation from the two-tensile-crack model. Observed (red arrows) and calculated (blue arrows) horizontal deformations from April 2006 to April 2009 based on the two-tensilecrack model. Red-and orange-colored rectangles denote the locations of the deep and shallow tensile cracks, respectively

From the above discussion, more dense and precise deformation data is prerequisite for detailed discussion. Therefore, we installed new leveling routes on the mountain area in October 2014 and April 2015 (Murase et al. 2015). Based on the improved data, the remaining issues will be performed in future studies.

Based on the GNSS data, MRI and JMA (2007) proposed a spherical source at a $0-\mathrm{km}$ depth and a dike at a $2.5-\mathrm{km}$ depth. In contrast, Ishikawa (2008) proposed a model of two dikes at depths of 0 and $4 \mathrm{~km}$. Since the observation period for each model was different, they produced different results. Our preferred model was estimated using deformation data from the longest period; thus, we believe that our modeling represents a suitable estimate for the stable source. However, deformations from short-lived shallow sources, as detected by MRI and JMA (2007) and Ishikawa (2008), could not be detected. The sill-like crack may have existed in a stable configuration in the shallow crust from 2006 to 2014. For this period, all models are consistent with the necessary deep dike.

A tensile crack model has already been estimated as a magma source at Mount Asama volcano, Japan (Murakami 2005). A tensile crack with a depth of about $2 \mathrm{~km}$ below the surface was estimated by continuous GNSS measurements around Mount Asama volcano from 1996 to 2004. Murakami (2005) proposed that buoyant bubble-rich magma surges episodically into the crack-shaped magma reservoir, then it loses the buoyancy through degassing process, and it finally drains back to the further depth. Such activity has a strong resemblance to that occurring at Mount Ontake volcano.
In addition, a spherical source with a depth of about $8 \mathrm{~km}$ below the surface was estimated based on the precise leveling surveys in Mount Asama volcano (Murase et al. 2007). The buoyant bubble-rich magma may supply episodically from the deep spherical source to the shallow tensile crack in Mount Asama volcano. In Mount Ontake volcano, a spherical source with a depth of about $10 \mathrm{~km}$ and a shallow dike were estimated based on GNSS in the period from November 2006 to January 2007 (GSI 2008). The magma may supply from the deep spherical source to the shallow tensile cracks in Mount Ontake volcano.

\section{Temporal changes in pre-eruptive processes before the 2014 eruption}

Distinct uplift began on the Kiso-Onsen and Yashikino routes in 2006 (Fig. 10a, c) and continued until at least 2009. Although a phreatic eruption occurred in Mount Ontake volcano in March 2007, the magnitude of eruption is really small. We believe that uplift continued after the 2007 eruption because the amount of volcanic gas emitted by the 2007 eruption may be too small to have a loss of the magma's buoyancy. From 2009 to 2014, the leveling survey was not conducted on the Yashikino route (Fig. 10b), while in August 2013, the leveling survey was conducted only on a part of the Kiso-Onsen route (BM205-BM310). The results suggest that the uplift trend continued between April 2009 and August 2013 (Fig. 10a). Therefore, the uplift may continue until at least August 2013, albeit without seismic activity at the summit area, after the small eruption event in 2007 (Fig. 10c).

From the results between August 2013 and October 2014, the subsidence occurred after August 2013 (Fig. 10a). We, however, found no evidence to decide the exact occurrence time of subsidence from the leveling result because the leveling surveys were only conducted in August 2013 and October 2014. We believe that the subsidence mainly occurred during the 2014 eruption because the record of the tiltmeter located in about $3 \mathrm{~km}$ southeast part of the eruptive fissures suddenly showed a decrease in the slope angle or deflation in the 2014 eruption (JMA 2014).

We compared the temporal changes in vertical deformation to baseline change detected by GNSS (Fig. 10e). A rapid expansion of the baseline was detected from December 2006 to March 2007. However, a significant change was not detected from March 2007 to September 2014. On the other hand, a minor inflation of the summit area was detected by the campaign GNSS survey from February 2007 to April 2007 (MRI and JMA 2007). The locations of GEONET benchmarks were too far to detect clear deformation, as the latter was localized to a very small region of the study area. Using campaign GNSS data from February 2007 to April 2007, MRI and JMA (2007) 
(a) Time series of vertical deformation on the Kiso-Onsen route

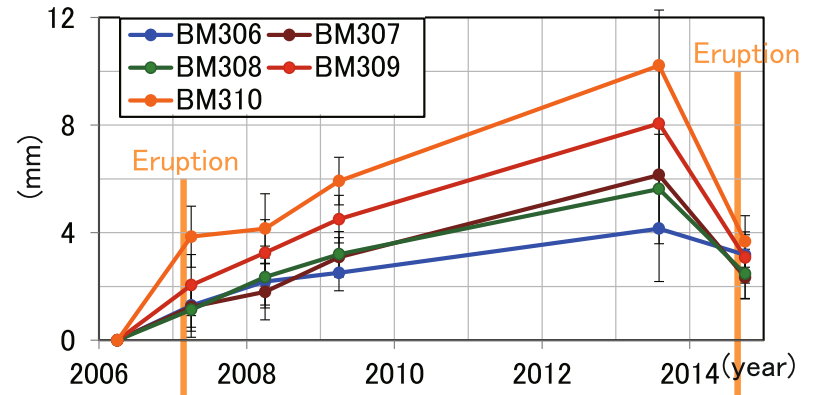

(b) Time series of vertical deformation on the Yashikino route

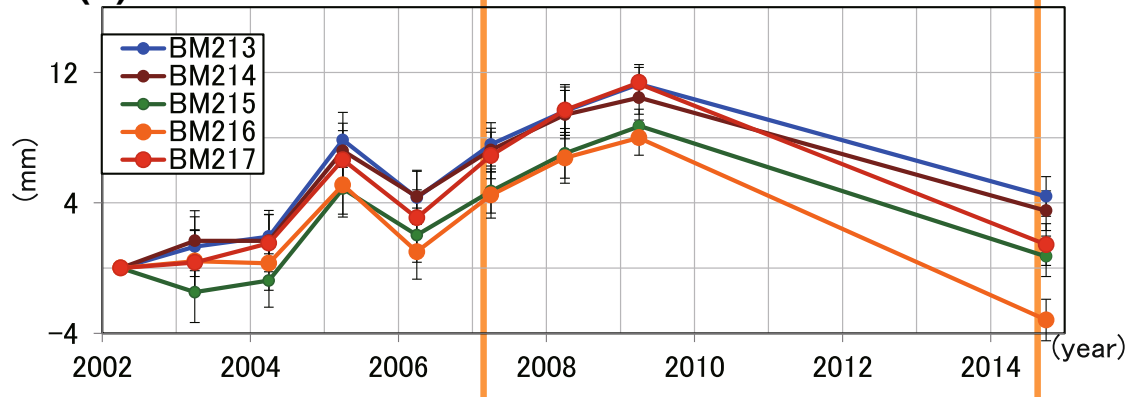

胥 120 (C) Time series of the seismic activity in the summit of the Ontake volcano

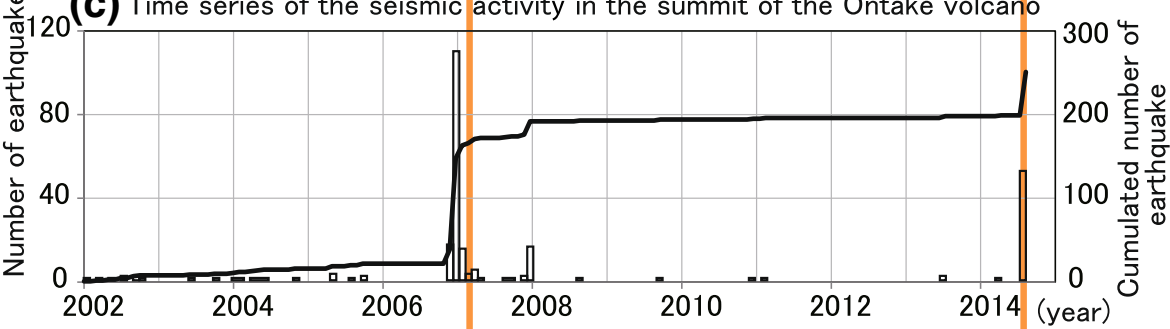

(d) Time series of the swarm activity in the east flank of the Ontake volcano

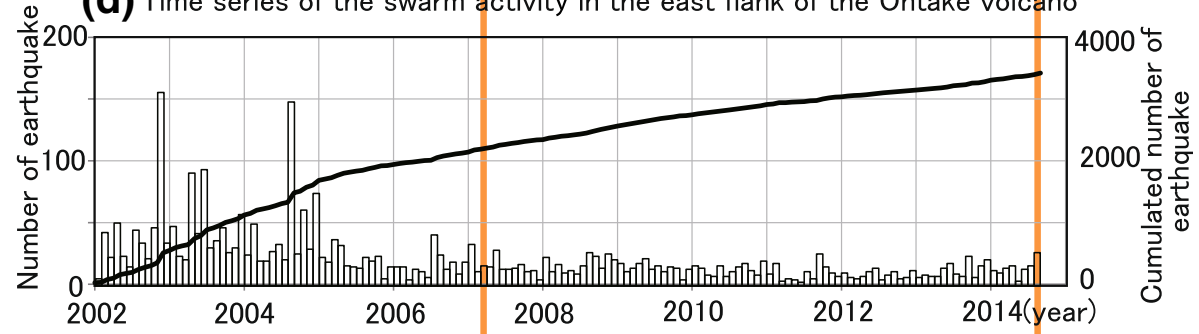

(e) Time series of baseline length of GNSS (Hagiwara-Mitake)

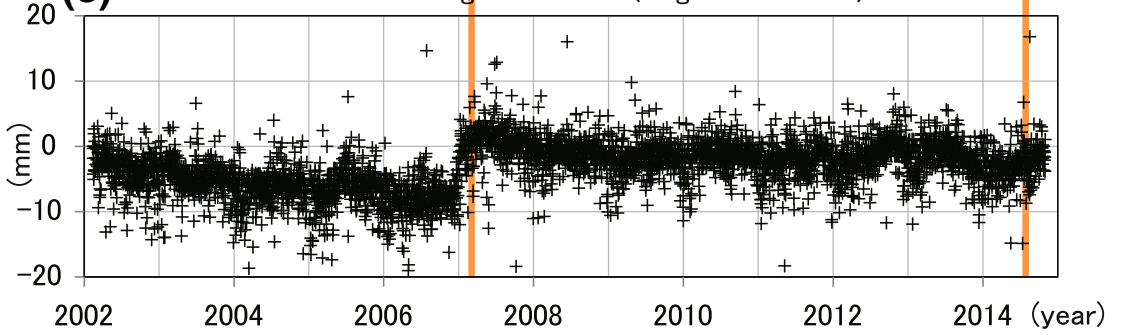

Fig. 10 Time series of deformation and earthquakes. a Time series of vertical deformation along the Kiso-Onsen route from April 2006 to October 2014. Relative deformation was measured with respect to the reference point (benchmark BM205). Benchmark numbers are shown in Fig. 1. Orange-colored bars denote the occurrence months of the eruptions in 2007 and 2014. b Time series of vertical deformation along the Yashikino route from April 2002 to October 2014. Relative deformation was measured with respect to the reference point (benchmark BM25). c The monthly number and cumulated number of earthquakes in the summit area of Mount Ontake volcano (rectangle $a$ in Fig. 1) from 2002 to September 2014. d The monthly number and cumulated number of earthquakes involved in swarm activity on the eastern flank of Ontake volcano (rectangle b in Fig. 1). e Time series of the baseline change between the Mitake GEONET benchmark relative to the Hagiwara GEONET benchmark 
proposed a shallow inflation source at a $0.1-\mathrm{km}$ depth. Uplift was only detected by the leveling survey from 2007 to 2013. This result is particularly important for the understanding of the preparatory process of the 2014 eruption.

We also briefly addressed deformation along the Yashikino route from 2002 to 2006. It was challenging to consider the preparatory process during the above period using a quantitative approach because deformation was affected by the seismic swarm activity that occurred close to the leveling routes (Fig. 10d). However, minor uplift can be roughly estimated from 2002 to 2006 (Fig. 10b), suggesting the preparatory process may have initiated prior to 2006.

\section{Possible scenarios of the preparatory process preceding the 2014 eruption}

Based on the rapid uplift from 2006 to 2007, magma may have ascend beneath the summit in December 2006, while deep and shallow tensile cracks rapidly expanded from December 2006 to March 2007. VT, LP, and VLP events may have been caused by the rapid expansion of cracks (Fig. 11a; Nakamichi et al. 2009).

Based on the smaller amount of uplift between 2007 and 2009, we inferred that a minor amount of magma was supplied continuously, allowing tensile cracks to slightly expand. The shallow source may have inflated during this period (MRI and JMA 2007). Based on the Kiso-Onsen route time series (Fig. 10a), we believe that this trend continued until August 2013. After the 2007 eruption, a minor inflation of the summit area was detected, not only by the leveling survey but also by the campaign GNSS (MRI and JMA 2007). However, the presence of expanded cracks from 2007 to 2013 had not been inferred until now.
The phreatic eruption occurred on 27 September 2014, and the shallow tensile crack may have deflated at this activity (Fig. 11c). VT and LP events might occur by the rising volcanic gases and fluids just above the deflated crack (Kato et al. 2015). From the leveling result, clear deformation caused by volume change of the deep crack was not detected. The deep crack may not change during this time.

We could not detect what kind of crustal deformation occurred immediately before, during, or after the 2014 phreatic eruption because the leveling surveys were only conducted in August 2013 and October 2014. Based on the continuous GNSS survey, clear deformations were not detected on GEONET benchmarks in the 2014 phreatic eruption because these locations are too far to detect it (Fig. 10e). In order to detect small deformation localized to a very small region around eruptive fissures, continuous GNSS surveys on the mountain area will be needed.

\section{Conclusions}

Significant uplift $(\sim 10 \mathrm{~mm})$ and subsidence $(\sim 8 \mathrm{~mm})$ were detected from 2006 to 2009 and 2009 to 2014, respectively, on the eastern flank of Mount Ontake volcano using precise leveling surveys. The most suitable model to explain the subsidence (2009-2014) was a sill-like tensile crack estimated to be $-4.7 \mathrm{~m}$ in opening, $1.5 \mathrm{~km}$ in width, $2.5 \mathrm{~km}$ in depth, and dipping at $-15^{\circ}$. A two-tensile-crack model best accounts for the uplift between 2006 and 2009. The geometry of the shallow crack was assumed to be the same as that of the sill-like tensile crack. The opening of the shallow crack was modeled to be $0.6 \mathrm{~m}$. The deep crack was estimated to be $0.7 \mathrm{~m}$ in opening, $2 \mathrm{~km}$ in length, $4.5 \mathrm{~km}$ in width, $3 \mathrm{~km}$ in depth, and with a dip of $70^{\circ}$.

Distinct uplift began in 2006 and was followed by seismic activity and a small phreatic eruption. This uplift

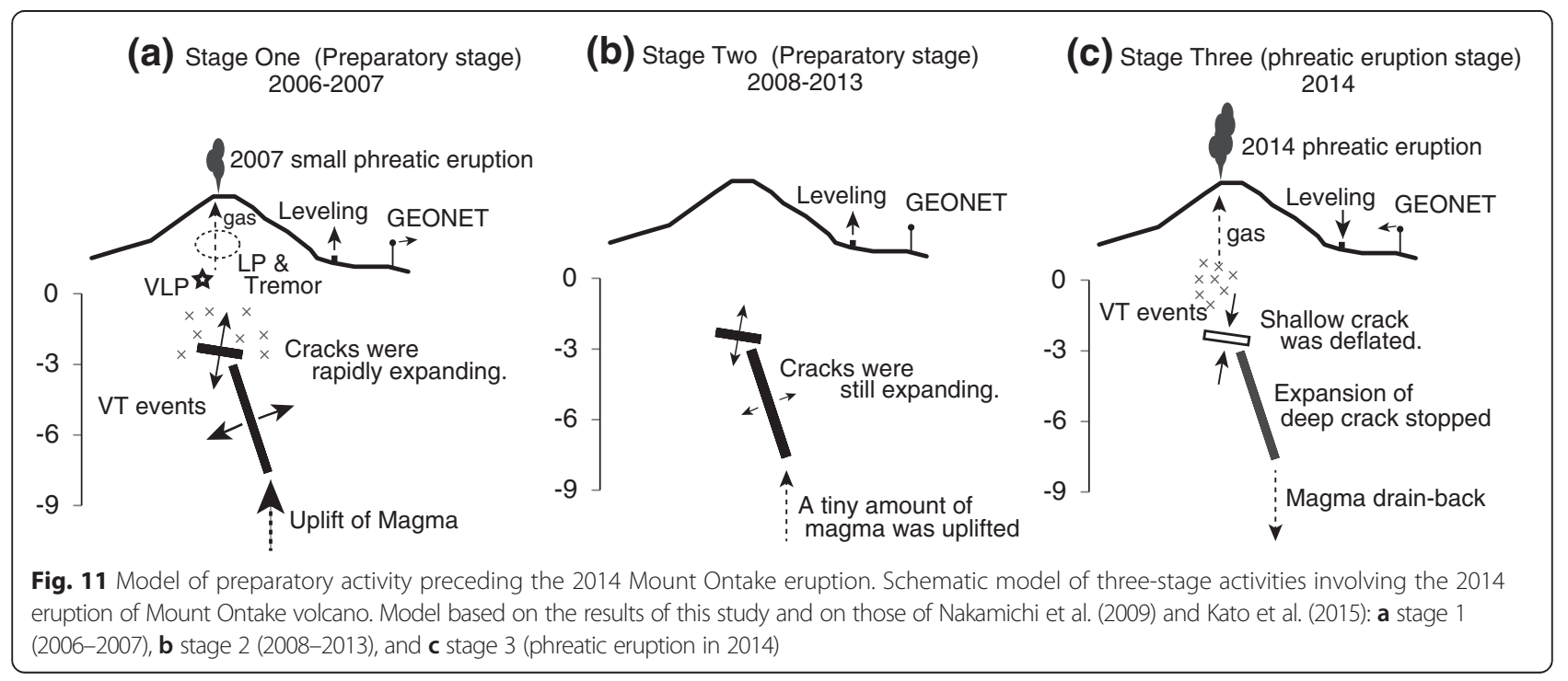


trend may have continued until August 2013; however, after the 2007 event, deformation was aseismic. The uplift from 2006 to 2013 suggests that magma ascended rapidly beneath the summit area in December 2006 and that deep and shallow tensile cracks expanded between 2006 and 2013. The results suggest that concurrent with the phreatic eruption of 27 September 2014, the shallow crack may have deflated.

The results of this study demonstrate that minor deformation detected by highly accurate and dense geodetic observations (e.g., precise leveling surveys) in mountainous areas can provide useful information for understanding preparatory activity preceding phreatic eruptions.

\section{Competing interests}

All authors declare that they have no competing interests.

\section{Authors' contributions}

MM carried out the leveling surveys and analysis of the leveling data and drafted the manuscript. FK designed the leveling routes, carried out the leveling surveys, and helped to draft the manuscript. YY carried out the leveling surveys and helped to draft the manuscript. SH and KM carried out the leveling surveys. TM, $\mathrm{HM}$, and TO carried out the leveling surveys and helped to draft the manuscript. SY, RM, HI, TM, and KU carried out the leveling surveys. KY and HN helped to draft the manuscript. All authors read and approved the final manuscript

\section{Acknowledgements}

We thank two anonymous referees for their careful reading of our manuscript and their numerous constructive suggestions that helped to improve this paper. We would like to thank the staff and students of Nagoya University for their support during the surveys. We gratefully acknowledge the Geospatial Information Authority of Japan for providing the F3 solutions from the GEONET benchmarks. We are also grateful to the Japan Meteorological Agency for providing the hypocenter catalogs. This research was partially supported by JSPS KAKENHI (26900002) and the Collaborative Research Program of Disaster Prevention Research Institute, Kyoto University (27G-03). Some figures were prepared using the generic mapping tools (GMT) package (Wessel and Smith 1995)

\section{Author details}

'Department of Geosystem Sciences, College of Humanities and Sciences, NIHON University, 3-25-40, Sakurajosui, Setagaya-ku, Tokyo 156-8550, Japan. ${ }^{2}$ Tono Research Institute of Earthquake Science, Association for the Development of Earthquake Prediction, 1-63, Yamanouchi, Akiyo-cho, Mizunami, Gifu 509-6132, Japan. ${ }^{3}$ Research Center for Seismology, Volcanology and Disaster Mitigation, Graduate School of Environmental Studies, Nagoya University, D2-2(510), Furo-cho, Chikusa-ku, Nagoya 464-8601, Japan. ${ }^{4}$ Institute of Seismology and Volcanology, Faculty of Sciences, Kyushu University, 2-5643-29 Shinyama, Shimabara 855-0843, Japan. ${ }^{5}$ Institute of Seismology and Volcanology, Graduate School of Science, Hokkaido University, Kita 10 Nishi 8, Kita-ku, Sapporo 060-0810, Japan. ${ }^{6}$ Aso Volcanological Laboratory, Graduate School of Science, Kyoto University, Kumamoto 869-1404, Japan. ${ }^{7}$ Sakurajima Volcano Research Center, Disaster Prevention Research Institute, Kyoto University, 1722-19 Sakurajimayokoyama-cho, Kagoshima 891-1419, Japan.

\section{Received: 6 October 2015 Accepted: 13 January 2016}

Published: 22 January 2016

\section{References}

Akaike $H$ (1973) Information theory and an extension of the maximum likelihood principle. In: Petrov BN, Csaki F (eds) 2nd International Symposium on Information Theory. Akademoai Kiado, Budapest., pp 268-281

Arnadottir T, Segall P (1994) The 1989 Loma Prieta earthquake imaged from inversion of geodetic data. J Geophys Res Solid Earth 99(B11):21835-21855
Battaglia M, Troise C, Obrizzo F, Pingue F, De Natale G (2006) Evidence for fluid migration as source of deformation at Campi Flegrei caldera (Italy). Geophys Res Lett 33, L01307, http://dx.doi.org/10.1029/2005GL024904

Daita Y, Tanada T, Tanbo T, Ito H, Harada M, Mannen K (2009) Temporal change of the pressure source estimated by tilt records during the 2001 Hakone swarm activity. Bull Volcanol Soc Jpn 54(5):223-234 (In Japanese with English abstract)

Fukui K, Sakai T, Yamamoto T, Fujiwara K, Takagi A, Churei M (2003) Availability and limitations of an elevation-modified Mogi model to estimate the pressure source from volcanic crustal deformation. Paper presented at the Volcanological Society of Japan 2003 Fall Meeting 35

Geospatial Information Authority of Japan (2008) Crustal deformation around Ontake volcano. Report of the Coordinating Committee for Prediction of Volcanic Eruption 96:36-39 (In Japanese)

Geospatial Information Authority of Japan (2015) Ontake volcano. Coordinating Committee for Prediction of Volcanic Eruption (In Japanese)

Goldberg DE (1989) Genetic algorithms in search, optimization, and machine learning. Addison Wesley, Reading, MA, p 401

Irwan M, Kimata F, Fujii N (2006) Time dependent modeling of magma intrusion during the early stage of the 2000 Miyakejima activity. J Volcanol Geoth Res 150:202-212

Ishikawa K (2008) Observation and examination of the crustal deformation around Ontake volcano and Tatun Volcano Group, Taiwan. MS Thesis, Nagoya University., p 37

Japan Meteorological Agency (2008a) Volcanic activity of Ontakesan Volcano-from December 2006 to February 2007. Report of the Coordinating Committee for Prediction of Volcanic Eruption 96:18-35 (In Japanese)

Japan Meteorological Agency (2008b) Volcanic activity of Ontakesan (from March 2007 to June 2007). Report of the Coordinating Committee for Prediction of Volcanic Eruption 97:14-29 (In Japanese)

Japan Meteorological Agency (2014) Volcanic activity of Ontakesan. Coordinating Committee for Prediction of Volcanic Eruption, (In Japanese)

Kato A, Terakawa T, Yamanaka Y, Maeda Y, Horikawa S, Matsuhiro K, Okuda T (2015) Preparatory and precursory processes leading up to the 2014 phreatic eruption of Mount Ontake, Japan. Earth Planets Space 67:111. doi:10.1186/ s40623-015-0288-x

Kimata F, Miyajima R (2001) Ground deformation detected by precise leveling around Ontake earthquake swarm area in September 1999 to April 2000. Bulletin of Tono Earthquake Science Institute 6:91-96 (In Japanese)

Kimata F, Miyajima R, Murase M, Irwan M, Darmawan D, Solim D, Ohta Y (2003) Vertical movements detected by precise leveling at the Ontake earthquake swarm area in the period of 1999-2003: upheaval at Yashikino Area. Bulletin of Tono Earthquake Science Institute 10:69-75 (In Japanese)

Kimata F, Miyajima R, Murase M, Darwaman D, Ito T, Ohata Y, Irwan M, Takano K, Ibrahim F, Koyama E, Tsuji H, Takayama T, Uchida K, Okada J, Solim D, Anderson H (2004) Ground uplift detected by precise leveling in the Ontake earthquake swarm area, central Japan in 2002-2004. Earth Planets Space 12:E45-E48

Kimata F, Miyajima R, Murase M, Ishikawa K (2011) Vertical deformation detected by precise leveling at the earthquake swarm area of eastern Ontake volcano in 2000-2009. Bulletin of Tono Earthquake Science Institute 27:67-72 (In Japanese)

Kimura J, Yoshida T (1999) Magma plumbing system beneath Ontake Volcano, central Japan. Island Arc 8:1-29

Matsumoto A, Kobayashi T (1995) K-Ar age determination of late Quaternary volcanic rocks using the "mass fractionation correction procedure": application to the Younger Ontake Volcano, central Japan. Chem Geol 125:123-135

Meteorological Research Institute of Japan, Japan Meteorological Agency (2007) Ontake volcano. Coordinating Committee for Prediction of Volcanic Eruption. (In Japanese)

Mogi K (1958) Relations between the eruptions of various volcanoes and the deformation of the ground surface around them. Bull Earthquake Res Inst 36: 99-134

Murakami M (2005) Magma plumbing system of the Asama Volcano inferred from continuous measurements of GPS. Bull Volcanol Soc Japan 50(5):347-361 (In Japanese, with English abstract)

Murase M, Ono K, Ito T, Miyajima R, Mori H, Aoyama H, Ohshima H, Yoshida Y, Terada A, Koyama E, Takeda T, Watanabe H, Kimata F, Fujii N (2007) Time-dependent model for volume changes in pressure sources at Asama volcano, central Japan due to vertical deformations detected by precise leveling during 1902-2005. J Volcanol Geoth Res 164:54-75

Murase M, Lin C-H, Kimata F, Mori H, Pu H-C (2014) Volcano-hydrothermal activity detected by precise leveling surveys at the Tatun volcano group in Northern Taiwan during 2006-2013. J Volcanol Geoth Res 286:30-40 
Murase M, Kimata F, Miyajima R, Mori H, Yamanaka Y, Horikawa S, Matsuhiro K, Ohkura T, Yoshikawa S, Inoue H, Mishima T, Sonoda T, Matsushima T, Uchida K (2015) Preparatory process for the 2014 eruption in Ontake Volcano estimated from precise leveling (2006-2014). Presented at the Japan Geoscience Union Meeting 2015, SVC45-15

Nagoya University (1999) Temporal variations of seismic activity in the southeastern Ontake volcano (1977-1998). Report of the Coordinating Community for Volcanic Eruption Prediction 74:64-68 (In Japanese)

Nakamichi H, Kumagai H, Nakano M, Okubo M, Kimata F, Ito Y, Obara K (2009) Source mechanism of a very-long-period event at Mt Ontake, central Japan: response of a hydrothermal system to magma intrusion beneath the summit. J Volcanol Geoth Res 187:167-177

Okada Y (1992) Internal deformation due to shear and tensile faults in a half-space. Bull Seism Soc Am 82:1018-1040

Pelton JR, Smith RB (1982) Contemporary vertical surface displacements in Yellowstone National Park. J Geophys Res 87:2745-2761

Sano Y, Nakamura Y, Wakita H, Urabe A, Tominaga T (1984) Helium-3 emission related to volcanic activity. Science 224:150-15

Vanicek P, Castle RO, Balazs El (1980) Geodetic leveling and its applications. Rev Geophys 18:505-524

Wessel P, Smith WHF (1995) New version of the Generic Mapping Tools released. Trans Am Geophys Union 76:329

Winter G, Periaux J, Galan M, Cuesta P (1996) Genetic algorithms in engineering and computer science. Wiley, 480

Yamada N, Kobayashi T (1988) Geology of the Ontakesan district. With geological sheet map at 1:50,000. Geol. Surv. Jpn., p 136, In Japanese, with English abstract

Yamamoto T (2014) The pyroclastic density currents generated by the September 27, 2014 phreatic eruption of Ontake Volcano, Japan. Bull Geol Surv Japan 65:117-127

Yamamoto K, Sonoda T, Takayama T, Ichikawa N, Ohkura T, Yoshikawa S, Inoue H, Matsushima T, Uchida K, Nakamoto M (2013) Vertical ground deformation associated with the volcanic activity of Sakurajima Volcano, Japan during 1996-2010 as revealed by repeated precise leveling surveys. Bull Volcanol Soc Japan 58(1):137-151

\section{Submit your manuscript to a SpringerOpen ${ }^{\circ}$ journal and benefit from:}

- Convenient online submission

- Rigorous peer review

- Immediate publication on acceptance

- Open access: articles freely available online

- High visibility within the field

- Retaining the copyright to your article

Submit your next manuscript at $\gg$ springeropen.com 